\section{Vitamin E and Respiratory Tract Infections in Elderly Persons}

To the Editor: Dr Meydani and colleagues ${ }^{1}$ reported the results of a vitamin $E$ trial involving residents in long-term care facilities. In a post hoc analysis, they observed a slightly lower common cold incidence in the group that was administered $200 \mathrm{IU} / \mathrm{d}$ of vitamin E (relative risk [RR], 0.83; 95\% confidence interval [CI], 0.68-1.01).

We examined the effect of vitamin E $(50 \mathrm{mg} / \mathrm{d})$ on common cold incidence in the Alpha-Tocopherol BetaCarotene Cancer Prevention Study cohort involving 21796 male smokers aged 50 to 69 years at baseline. ${ }^{2}$ We found no overall effect of vitamin $E$ on common cold incidence (RR, 0.99; 95\% CI, 0.98-1.01). However, in an exploratory subgroup analysis, we found a statistically significant but clinically modest reduction of common cold incidence in city-dwelling participants aged 65 years or older who smoked less than 15 cigarettes/d (RR, 0.72; 95\% CI, 0.62-0.83), with no effect among elderly participants living outside cities or smoking more than 15 cigarettes/d (RR, 0.99; 95\% CI, 0.941.05).

Although these 2 studies suggest that vitamin E might reduce the risk of the common cold by $20 \%$ in some subgroups of the elderly population, we consider this a small effect. Given an annual incidence of 1 cold per person, 5 persons would need to take up to $200 \mathrm{IU} / \mathrm{d}$ of vitamin E for 1 year to prevent 1 episode of the common cold, which is usually a short and self-limiting nuisance.

\section{Harri Hemilä, MD, PhD \\ harri.hemila@helsinki.fi \\ Jaakko Kaprio, MD, PhD \\ Department of Public Health \\ University of Helsinki \\ Helsinki, Finland}

1. Meydani SN, Leka LS, Fine BC, et al. Vitamin $\mathrm{E}$ and respiratory tract infections in elderly nursing home residents: a randomized controlled trial. JAMA. 2004;292: 828-836.

2. Hemilä H, Kaprio J, Albanes D, Heinonen OP, Virtamo J. Vitamin C, vitamin E, and beta-carotene in relation to common cold incidence in male smokers. Epidemiology. 2002;13:32-37.

In Reply: There are several major differences in study design as well as reported results between our study and that of Hemilä et al. ${ }^{1}$ Their study was designed to determine the effect of vitamin $\mathrm{E}$ and beta-carotene on lung cancer in middle-aged and elderly (50-69 years) male smokers; our study was limited to the elderly population ( $\geq 65$ years), included both smokers and nonsmokers as well as both men and women, and had incidence of respiratory tract infection as the primary outcome. Our study used a higher daily dose of vitamin $\mathrm{E}$ than their study (200 IU/d of DL- $\alpha$ tocopherol vs $50 \mathrm{mg} / \mathrm{d}$ of $\alpha$-tocopherol). We used $200 \mathrm{IU} / \mathrm{d}$ because this dose had been demonstrated in an earlier study to induce the most robust improvement in immune function in the elderly population. ${ }^{2}$ In their study, the common cold incidence data were based on recall by the partici- pants during thrice-annual visits; in contrast, we prospectively collected data once a week by means of an interview, focused physical examination, and chart review. Additionally, we assessed compliance with vitamin E supplementation by 3 different methods. Finally, while their study reported a reduction in the incidence of common colds only in elderly male smokers who resided in cities, we found a reduction in risk of acquiring common colds in the elderly regardless of sex or smoking status.

We agree with Drs Hemilä and Kaprio that the reduction in the incidence of the common cold by vitamin E was moderate. However, in addition to decreasing the incidence per participant of common cold, vitamin E supplementation reduced the number of participants acquiring upper respiratory tract infection by $16 \%$ among all randomized participants. Given that 34 million elderly people live in nursing homes, ${ }^{3}$ this would translate into more than 5 million fewer elderly nursing home residents contracting upper respiratory tract infections in a year.

In addition, we disagree that the common cold is a short and self-limiting nuisance in the elderly population. Falsey et $\mathrm{al}^{4}$ reported an average of 14 days for rhinovirus/ coronavirus infection in frail elderly individuals. Because of the high attack rate, non-influenza-related viral upper respiratory tract infections are responsible for a substantial economic burden in the elderly population. ${ }^{5}$ In addition, there is growing evidence that colds in elderly individuals are often complicated by lower respiratory tract illness, ${ }^{6}$ which may be severe in those with underlying lung disease ${ }^{7}$ and lead to hospitalization. ${ }^{8}$

Davidson H. Hamer, MD

Center for International Health and Development

Boston University School of Public Health

Simin Nikbin Meydani, DVM, PhD

simin.meydani@tufts.edu

Nutritional Immunology Laboratory

Jean Mayer USDA Human Nutrition Research Center on Aging Tufts University

Boston, Mass

1. Hemilä $H$, Kaprio J, Albanes D, Heinonen OP, Virtamo J. Vitamin C, vitamin E, and beta-carotene in relation to common cold incidence in male smokers. Epidemiology. 2002;13:32-37.

2. Meydani SN, Meydani M, Blumberg JB, et al. Vitamin E supplementation and in vivo immune response in healthy elderly subjects: a randomized controlled trial. JAMA. 1997;277:1380-1386.

3. Kinsella K, Velkoff VA. An Aging World: 2001. Washington, DC: US Census Bureau; 2001

4. Falsey AR, McCann RM, Hall WJ, et al. The "common cold" in frail older persons: impact of rhinovirus and coronavirus in a senior daycare center. J Am Geriatr Soc. 1997:45:706-711.

5. Fendrick AM, Monto AS, Nightengale B, Sarnes M. The economic burden of non-influenza-related viral respiratory tract infection in the United States. Arch Intern Med. 2003;163:487-494.

6. Nicholson KG, Kent J, Hammersley V, Cancio E. Acute viral infections of upper respiratory tract in elderly people living in the community: comparative, prospective, population based study of disease burden. BMJ. 1997;315:1060-1064.

7. Wald TG, Shult P, Krause P, Miller BA, Drinka P, Gravenstein S. A rhinovirus outbreak among residents of a long-term care facility. Ann Intern Med. 1995;123: 588-593.

8. Falsey AR, Walsh EE, Hayden FG. Rhinovirus and coronavirus infectionassociated hospitalizations among older adults. J Infect Dis. 2002;185: 1338-1341. 